\title{
Risk mapping of dengue in Selangor and Kuala Lumpur, Malaysia
}

\author{
Hafiz Hassan ${ }^{1}$, Shamarina Shohaimi², Nor R. Hashim ${ }^{1}$ \\ ${ }^{1}$ Department of Environmental Science, Faculty of Environmental Studies, Putra University, Serdang, Malaysia; \\ ${ }^{2}$ Department of Biology, Faculty of Science, Putra University, Serdang, Malaysia
}

\begin{abstract}
Dengue fever is a recurring public health problem afflicting thousands of Malaysians annually. In this paper, the risk map for dengue fever in the peninsular Malaysian states of Selangor and Kuala Lumpur was modelled based on co-kriging and geographical information systems. Using population density and rainfall as the model's only input factors, the area with the highest risk for dengue infection was given as Gombak and Petaling, two districts located on opposite sides of Kuala Lumpur city that was also included in the risk assessment. Comparison of the modelled risk map with the dengue case dataset of 2010, obtained from the Ministry of Health of Malaysia, confirmed that the highest number of cases had been found in an area centred on Kuala Lumpur as predicted our risk profiling.
\end{abstract}

Keywords: dengue fever, geographical information systems, risk mapping, population density, rainfall, Malaysia.

\section{Introduction}

Dengue fever is a human, febrile illness caused by one of four strains of the dengue virus (DEN-1 to DEN-4), transmitted by the Aedes mosquito vectors. The course of the disease seems to be regulated by interplay of these four serotypes producing symptoms that include increased body temperature, headache, rashes and pain comprising the motor system. Dengue haemorrhagic fever (DHF) is a deadly form that can present with severe complications, including internal and external bleeding leading to the dengue shock syndrome (DSS), which is fatal due to extreme loss of blood (Whitehorn and Farrar, 2010). The geographical areas affected by this disease together form the so called "dengue belt" near the equator that includes the lower east coast of the United States and tropical countries in South America, North Africa and southern Asia (WHO, 1993). The number of cases has grown dramatically around the world in recent years and, in the absence of drugs and vaccines with effect against this disease, dengue fever cannot easily be controlled. It is currently estimated that there are 500 million cases worldwide with 2.5 billion people at risk for infection every year (WHO, 2012). The dis-

Corresponding author:

Nor R. Hashim

Department of Environmental Science,

Faculty of Environmental Studies, Putra University

Serdang, Malaysia

Tel./Fax +60176567996

E-mail: heritagecolony@gmail.com ease is particularly common in Southeast Asia. Malaysia has a pronounced dengue problem since its first epidemic in the 1970s according to the Ministry of Health in Malaysia (MoHM, 1986). Between 1962 and 1972, an average of 19.4 cases was reported per year in Peninsular Malaysia, with the majority in the states of Johor, Melaka and Selangor (MoHM, 1986). In the 1980s, a biannual pattern was seen, in which case numbers and death tolls peaked every two years before becoming irregular later in the decade (MoHM, 1986). Besides the humid and rainy climate, which is suitable for the Aedes vector, the unsanitary conditions of the many homes provide suitable breeding sites for the mosquitoes, which account for $70 \%$ of larvae found during inspections (Director-General of Health, Malaysia, 2010). The urbanized areas of Selangor and Kuala Lumpur are the most populated states in Peninsular Malaysia, owing to increasing economic opportunities and various developments that attract people. As a result, people settle in these areas, particularly in Klang Valley, a recently urbanized area characterised by high economic activity and high population density (Selangor State Investment Centre, 2005). Another factor facilitating the spread of infectious diseases is the abundance of rapid and far-reaching transportation networks such as roads and railways as well as connections served by airplanes and ships. The Aedes vector is currently closely monitored in the whole country as it presents an immediate risk for the human population (Zhawir and Hadafi, 2009). A top-down view of the situation on the ground is crucial for insights into the bigger 
picture when attempting to monitor infectious diseases. However, health authorities must often deal with more outbreaks than they have resources for (time and manpower). Mapping and spatial analysis are powerful means that can alleviate part of this problem, in particular as diseases vary over large areas adapting to diverse geography, land use, accessibility and demography. According to World Health Organization (WHO), the application of geographical information systems (GIS) is useful for visualizing spatial disease distributions and facilitating effective monitoring and evaluation of the situation at hand (WHO, 1993). Thus, it can be argued that disease incidence can be explained by the relationship between pathological factors (pathogens) and geographic factors (geogens), which both influence the distribution of various diseases (Meade and Earickson, 2000). In field surveys, GIS can assist ground workers to pinpoint focal risk areas and show the spatial distribution of cases on maps, which maximise resources and manpower. GIS is also useful for outbreak investigations by smoothing the progress in assessing probable, causal factors for local diseases (Lloyd and Yu, 1994). Many studies and practical GIS applications have already been carried out with regard to dengue fever in Malaysia, e.g. spatial mapping in Sepang based on mathematical modelling by Dom et al. (2010) picturing areas of high and low risk, including the dynamic variation of the disease over time.

This research was undertaken to create a map of the distribution of dengue fever in Selangor and Kuala Lumpur for 2009 and 2010, aiming at the identification and visualizing areas of risk. The map was generated with the specific purpose for it to be utilized as a tool for decision-making and management of ground teams engaged in vector control.

\section{Materials and methods}

\section{Study site}

The states of Selangor and the Federal Territory of Kuala Lumpur (WPKL) in Malaysia (Fig. 1) constituted the area of this study. It was chosen since these two states have the highest annual number of dengue fever cases in Malaysia. WPKL is situated inside the state of Selangor, which means that both areas are in the same general region from the transmission point of view. It was felt that an exclusive analysis of Selangor would be erroneous as that would leave the middle region empty. Therefore, both territories were considered and

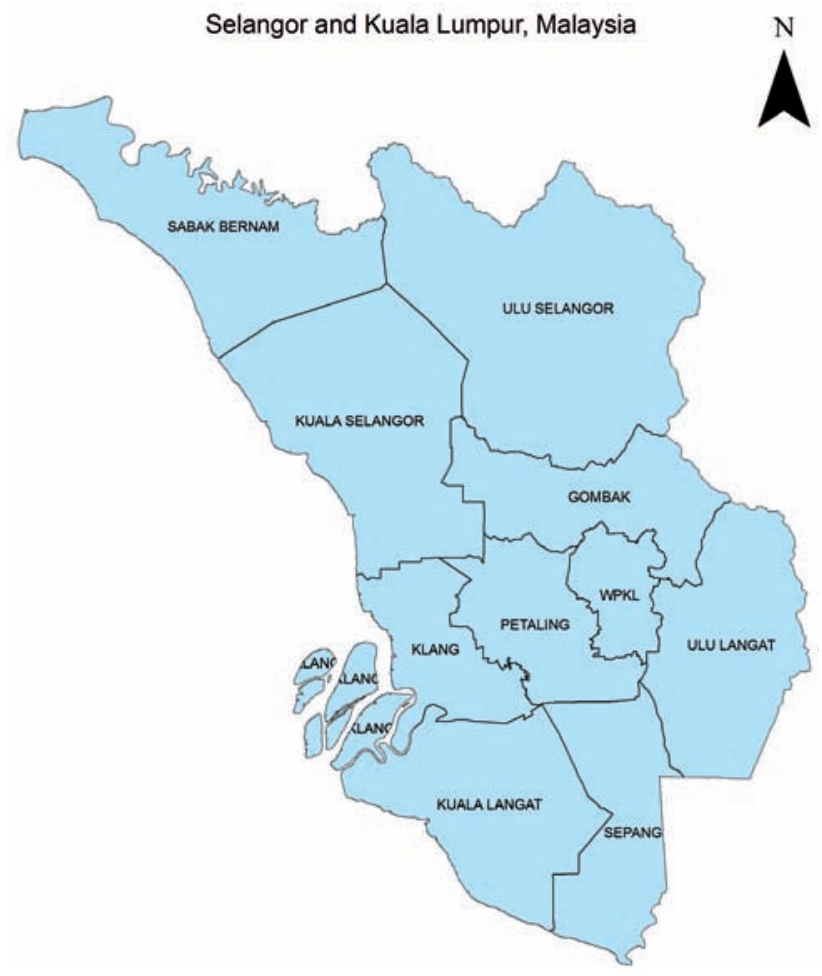

Fig. 1. Location of the study area in Malaysia showing the districts in the states of Selangor and Kuala Lumpur.

analysed as one. The districts of Ulu Langat $(1,320$ $\left.\mathrm{km}^{2}\right)$, Petaling $\left(2,980 \mathrm{~km}^{2}\right)$ and Gombak $\left(1,050 \mathrm{~km}^{2}\right)$ surrounding WPKL $\left(240 \mathrm{~km}^{2}\right)$ at the centre of the region were of particular interest as they have high population densities and therefore assumed to strongly increase the risk of dengue outbreaks (Table 1). Kuala Selangor $\left(160 \mathrm{~km}^{2}\right)$, Ulu Selangor $\left(100 \mathrm{~km}^{2}\right)$ and Sabak Bernam $\left(130 \mathrm{~km}^{2}\right)$, situated north of the centre, have lower population numbers.

Table 1. Population, area and population density of the districts in Selangor and Kuala Lumpur (2010).

\begin{tabular}{lrrr}
\hline District & Population & Area $\left(\mathrm{km}^{2}\right)$ & Population $/ \mathrm{km}^{2}$ \\
\hline Gombak & 653,633 & 1,051 & 621.8 \\
Klang & 784,957 & 1,252 & 627.2 \\
Kuala Langat & 221,564 & 261 & 850.3 \\
Kuala Selangor & 187,563 & 160 & $1,173.3$ \\
Petaling & $1,493,106$ & 2,981 & 500.95 \\
Sabak Bernam & 127,769 & 130 & 987.3 \\
Sepang & 135,805 & 229 & 594.0 \\
Ulu Langat & $1,116,012$ & 1,322 & 844.2 \\
Ulu Selangor & 183,546 & 104 & $1,761.4$ \\
Kuala Lumpur & $1,468,348$ & 242 & $6,059.3$ \\
Total & $6,372,303$ & 7,730 & $14,019.9$ \\
\hline
\end{tabular}


(i) Spatial data

A digital map of Malaysia at the scale of 1:10,000, with the political district boundaries marked, was obtained from the Department of Survey and Mapping in Malaysia (JUPEM). The projection was Kertau RSO Malaya Metres, a geodetic datum used in Malaysia and Singapore that has a conversion of 0.914398 metres per yard.

(ii) Dengue cases

Data for incidence and location of dengue fever cases in Selangor and WPKL for 2010 were taken from the Weekly Epidemiological Report, issued by the Selangor and Kuala Lumpur health offices (Table 1).

(iii) Local human population

Population data were obtained from the Annual Compendium of Environment Statistics, an annual publication by the Malaysian Department of Statistics.

(iv) Rainfall

This information was provided by the Meteorological Department of Malaysia listing the total annual rainfall for all weather stations in Selangor and Kuala Lumpur.

\section{Approach}

Using the Attribute Editor of ArcGIS 9.2 software (ESRI, Redlands, CA, USA) the data for disease population were transferred into the corresponding shape files representing the districts. The number of people in the study area was defined as 'population density' taking into account the varying populations and area sizes in each district. The dengue rate was estimated as the number of dengue cases per 100,000 of the population per year (January to December) of each year, i.e. calculated as:

$$
\begin{gathered}
\text { Dengue rate } \times 100,000= \\
\text { number of cases/total population }
\end{gathered}
$$

The resulting number is thus the ratio of the total number of infected population per 100,000, which normalises between the different populations of each district. Rainfall data, displayed as points, were interpolated from weather station data using the kriging method (Krige, 1951; Matheron, 1989) to produce mathematical estimates of the rainfall in areas around locations not covered by hard data. The risk map was created using co-kriging, modelling the population

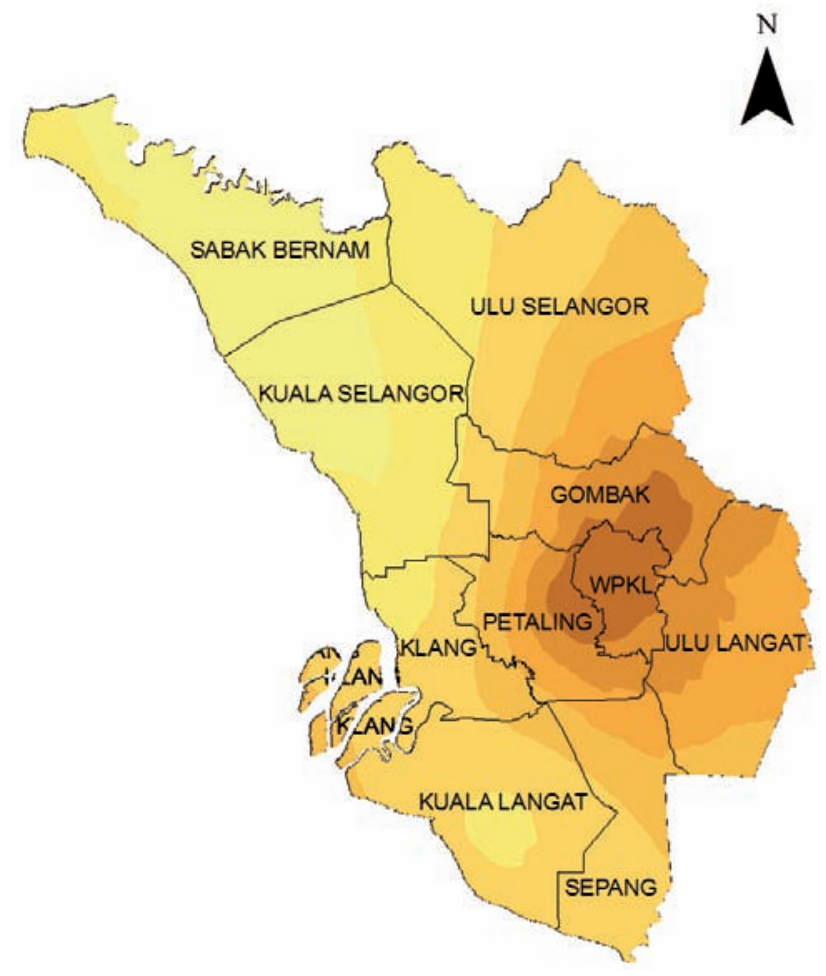

Fig. 2. Map representing the risk for dengue based on population density and rainfall (darker shades delineate higher risk).

density and rainfall map against the dengue rate map (Fig. 2). To assess its accuracy, this map was compared with the absolute number of cases recorded and the actual dengue rate for 2010 .

\section{Results}

The risk map, produced as described above, indicates that the risk for dengue should be high in WPKL and the parts of the surrounding districts Gombak and Petaling. The middle regions of both Selangor and Kula Lumpur are areas with high population densities and high rainfall, which would therefore be more likely to also have high dengue rates (Fig. 2).

A comparison between the risk map and the actual dengue rate (calculated by equation no. 1), indicates that the rates are the highest in the middle area, except for WPKL, and stretching southwards, while Ulu Selangor and Kuala Selangor present the lowest rate (Fig. 3). Sabak Bernam, although predicted to have very low risk presents in fact a medium level of dengue rate, while the surrounding districts of Ulu Langat, Petaling and Gombak show high rates.

Compared against the actual number of dengue cases, the risk map is closer to reality (Fig. 4). The districts Petaling, Ulu Langat and Gombak, which sur- 


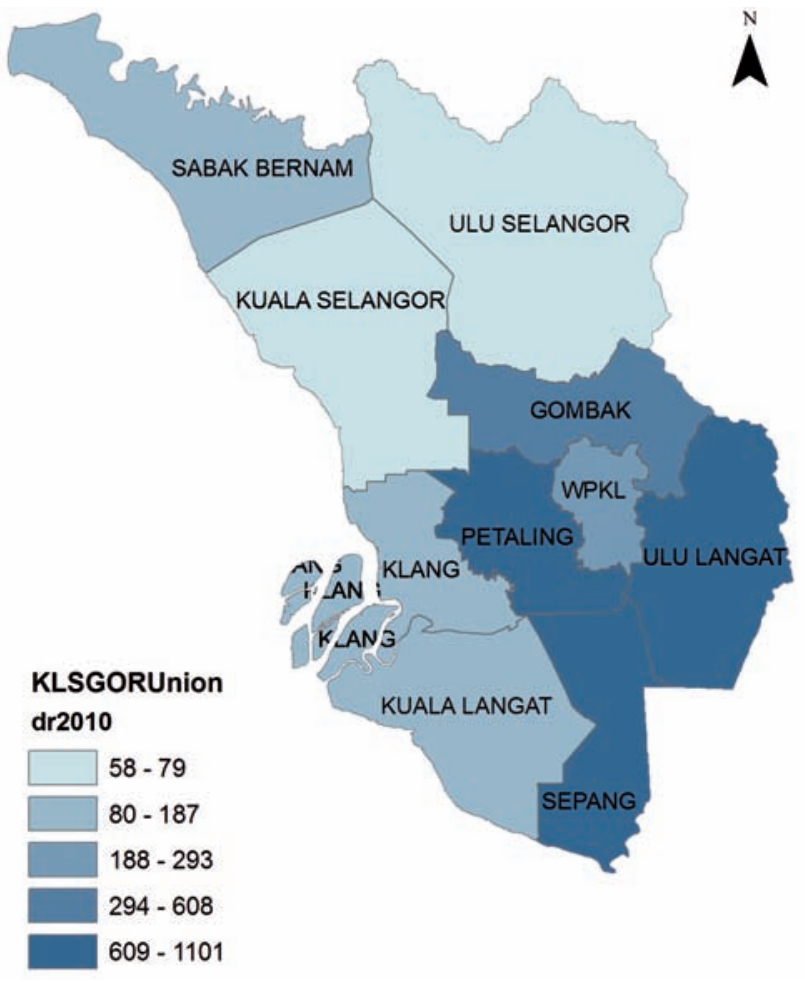

Fig. 3. KLSGORUnion dr2010 (Kuala Lumpur and Selangor, dengue rate 2010)

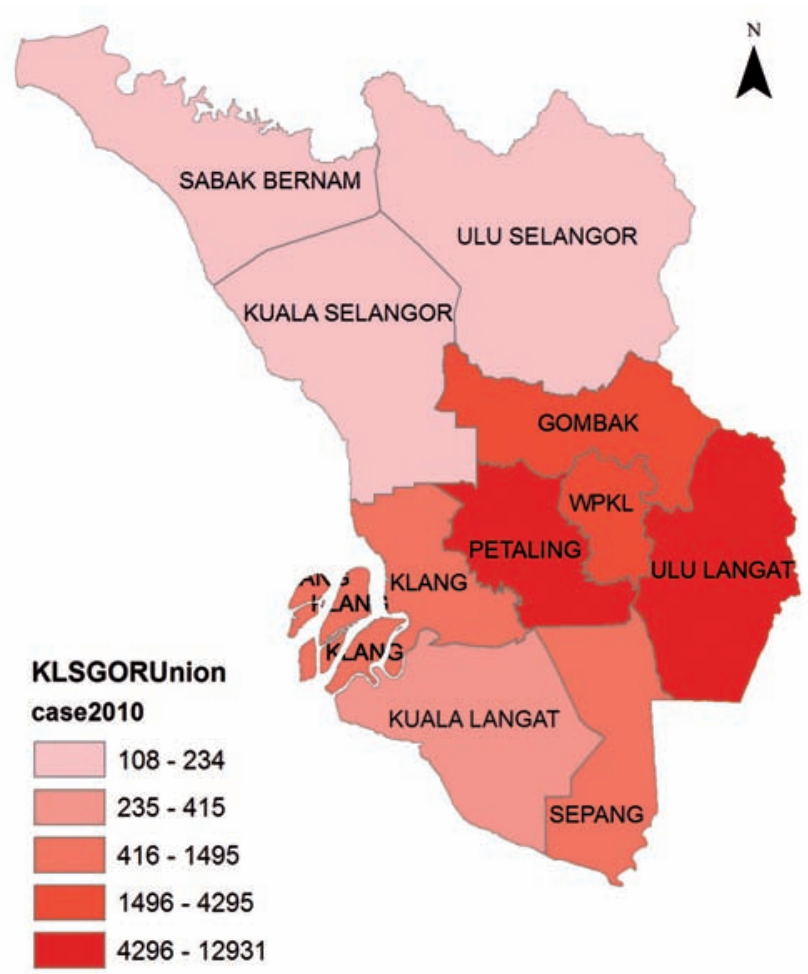

Fig. 4. KLSGORUnion dr2010 (Kuala Lumpur and Selangor, actual cases 2010) round WPKL at close range, were confirmed to have high numbers of cases, while districts further away (Kuala Selangor and Sabak Bernam) had lower numbers. Ulu Selangor was deemed to be an anomaly due to the fact that that it had a low case number despite a relatively high risk-rating. The number of cases in WPKL was a little lower than expected despite being at the middle of the region.

\section{Discussion}

For the general public and fringe personnel such as city management, mapping is useful for risk communication as it helps to disseminate information in a readily understandable format. The identification of highrisk areas can be prioritized against low-risk areas in resource allocations ensuring effective pro-active actions corresponding to the risk of the upcoming threat, rather than a reaction towards an occurred event of outbreak.

Naturally, the risk map does not coincide exactly with the dengue rate or the actual case counts. For example, Ulu Selangor had a low case number despite a high risk-rating and the number of cases in WPKL was lower than expected despite being at the middle of the region. This could be due to factors not included in our analysis, but in the case of WPKL it could be argued that the reason was the big city environment in the country capital or increased activity of the enforcement agencies and anti-dengue campaigns conducted throughout the year.

Population density in itself is a good measure of risk in our opinion. A bite from an infected Aedes mosquito does not always result in overt disease, but it does make anyone a dengue virus reservoir and thus a potential infection source. Therefore, considering all people a potential risk (as they can be healthy carriers just as well as uninfected) emphasises the higher probability of anyone in a crowd to become infected and supports the notion of a direct, positive correlation between population density and risk for outbreaks. Thus, the risk in the centre of the region, including the WPKL and the surrounding districts Ulu Langat, Petaling and Gombak, is high compared to Kuala Selangor and Sabak Bernam, and so is the highly developed and urbanized area of Klang Valley, where transmission of the virus is high due to the proximity of many confirmed and potential carriers.

High volume of rainfall increases Aedes survival by providing more breeding sites. Puddles and stagnant water in discarded containers of various kinds serve as nuclei of future generations of mosquitoes. As the 
Klang Valley is continuously developing, the construction sites for new and ongoing infrastructural projects pose a threat due to lack of sanitation. The risk map visualizes the background to the analyses described here resulting in forecasts of dengue fever events in Selangor and Kuala Lumpur. Although based on only population and rainfall, this risk map has been shown capable of general predictions of high-risk areas. The particular high risk found in the centre of the region and its vicinity confirms the usefulness of considering these two factors. Still, further improvement of analysis and increased accuracy of the risk map could be made by including more confounding factors. An early warning system (EWS) for future outbreaks, for example, would perhaps require increased certainty and thus need a more refined technique for approximation in situations with limited input from field surveys.

With early prevention steps, such as dealing with breeding spots at places shown to receive high volumes of rainfall, the impact of outbreaks can be reduced. In areas with high population density, community-centred awareness campaigns are the best way to alert the population and make them take precautions with respect to the risk for dengue transmission. The population growth will with all probability continue in the future, inflating the current population density further and rendering the problem more acute.

\section{Acknowledgements}

We would like to thank the staff from the Kuala Lumpur Health Office, especially Environmental Health Officer Muhammad Shafizi Abdul Wahab, Deputy Environmental Health Officer Amirul Hisham Mohd Eisa, Deputy Director of Health (Public Health) Dr. Zainol Ariffin Pawanchee and the staff from the Vector Diseases Unit for their assistance and cooperation. We would also like to thank the staff from the library of Malaysian Meteorological Department for providing priceless information.

\section{References}

Director-General of Health, Malaysia, 2010. Press release from Ministry of Health, Malaysia for week 52, 2010. Available at http://www.moh.gov.my/press_releases/94 (accessed on January 2011).

Dom NC, Abu Hassan AA, Rabiatul AIR, 2010. Spatial mapping of temporal risk characteristic of dengue cases in Subang Jaya. Proceedings of the International Conference of Science and Social Research 2010. Research Management Institute, University Technology MARA, pp. 361-366.

Lloyd O, Yu T, 1994. Disease mapping: a valuable technique for environmental medicine. J Hong Kong Med Assoc 46, 3-15.

Krige DG, 1951. A statistical approach to some mine valuations and allied problems at the Witwatersrand. MSc thesis thesis of the University of Witwatersrand, South Africa.

Matheron G, 1963. Principles of geostatistics. Econ Geol 58, 1246-1266.

Meade M, Earickson R, 2000. Medical geography. The Guilford Press.

MoHM, 1986. Prevention and control guide for dengue fever/ dengue hemorrhagic fever. Kuala Lumpur: Vector-Borne Disease Unit, Ministry of Health, Malaysia.

Selangor State Investment Centre, 2005. Opportunities of Investment in Selangor. Available at: http://ssic.my (accessed on October 2010).

Shaharudin I, Shamsul A, Tahir A, Mariam M, Azah D, Nik Shamsidah N, 2002. Geographical information systems (GIS) and the public health sector: dengue fever studies in Bandar Baru Bangi and Kajang. Malaysian J Pub Health Med 1, 34-42. Whitehorn J, Farrar J, 2010. Dengue. Br Med Bull 96, 161-173. WHO, 1993. Global Responses for Dengue Fever. Available at: http://www.who.int/csr/disease/dengue/en/index.html (accessed on October 2010)

WHO, 2012. Dengue and severe dengue. Fact sheet $\mathrm{N}^{\circ} 117$, last updated January 2012.

Zahawir A, Hadafi M, 2009. Applications of remote sensing and GIS for dengue epidemic surveillance in Petaling Jaya, Malaysia. MSc thesis. Serdang: University of Putra, Malaysia. 